\title{
Inhibitory effects of polar and non-polar organic substances on activated sludge activity
}

\author{
V. Inglezakis*, A. Kudarova*, D. Tarassov*, A. Jetybayeva*, Y. Myngtay* and D. Zhalmuratova* \\ * Chemical Engineering Department, School of Engineering, Nazarbayev University, 010000, Astana, \\ Kazakhstan \\ (E-mail: vasileios.inglezakis@nu.edu.kz)
}

\begin{abstract}
As is well known, several organic compounds, more often found in industrial wastewater, exhibit inhibitory effects on biomass activity, therefore leading to poor wastewater treatment efficiency. This study presents the experimental results on the inhibition effects of several polar and non-polar organic compounds on the activity of activated sludge. The organic compounds tested are: phenol, nitrophenol, resorcinol, dioxane, acetonitrile and benzotriazole (polar) and toluene, styrene, cyclohexane, paraxylene, benzene, and hexane (nonpolar). The experiments were conducted in a batch system under continuous aeration and stirring. The results showed that 11 out of 13 compounds inhibited the activated sludge activity. Polar compounds resulted in considerable inhibition while non-polar compounds either have no effect on activated sludge activity or exhibit some inhibition and only in high concentrations.
\end{abstract}

Keywords

Recycle activated sludge; inhibition; OUR; organic compounds

\section{INTRODUCTION}

The biological treatment is one of the most widely used processes for the removal of organic pollutants from wastewater. The microorganisms of the activated sludge are usually bacteria, protozoa and rotifers (Kraigher et al., 2008; Yao et al., 2010). Currently a large amount of organic contaminants present in wastewater are largely generated in industrial plants and if not treated properly may lead to inhibition of biomass activity, therefore leading to poor effluent quality (Surerus, 2009).

From the literature review, it can be concluded that the inhibitory effects of heavy metals such as chromium, cadmium, copper and nickel has been extensively studied. On the other hand, not all organic compounds that are widely used and produced in effluents of many petrochemical and processing industries have been studied due to complexity of composition of industrial wastewater mixture. These organic compounds may have highly toxic nature, hardly degraded and could cause significant inhibition of activated sludge activity, and thus should be treated properly before discharge to environment (Cai et al., 2010). Table 1 presents the inhibitory effects of commonly known organic compounds on activated sludge activity.

There are several methods for studying activated sludge activity. These include respiration tests of sludge, OUR, NUR (Nitrogen Uptake Rate), AUR (Ammonia Uptake Rate) experiments. The experimental reactors used are also diverse, such us batch and continuous flow. Furthermore, the sludge used in several studies is different, such as primary activated sludge, acclimatized activated sludge and modified prepared activated sludge (Cai et al., 2010; Ramteke and Gogate, 2015). Among all the approaches the respirometric method has attracted more attention (Cokgor et al., 2007). This method is based on the principle of the activated sludge respiration activity inhibition in 
Table 1. Inhibitory effects of some organic compounds on activated sludge activity (Bijing et al., 2010; Babaee et al. 2010).

\begin{tabular}{|c|c|}
\hline Compound & Inhibitory effect \\
\hline Aniline & $\begin{array}{l}\text { Inhibition concentration (IC) at } 30 \mathrm{~min} \text { time interval was } 2.783 \mathrm{~g} / \mathrm{L} \text {, sOUR decreased rapidly at } \\
<10 \mathrm{mg} / \mathrm{L} \text {, the inhibition continued but sOUR slowed down at } 10 \mathrm{mg} / \mathrm{L}-2000 \mathrm{mg} / \mathrm{L}\end{array}$ \\
\hline Benzotriazole & $\begin{array}{l}\text { Activated sludge biodegraded benzotriazole using both molecular oxygen and nitrate as } \\
\text { electron donors (SRT-72 h) }\end{array}$ \\
\hline Benzene & $\begin{array}{l}50 \% \text { inhibition concentration }\left(\mathrm{IC}_{-50}\right) \text { for } \mathrm{IC}_{50}-\mathrm{M}(24 \mathrm{~h}) \text { is } 1.497 \mathrm{~g} / \mathrm{L} \text { and for } \mathrm{IC}_{50}-\mathrm{S}(30 \mathrm{~min}) \text { is } \\
0.235 \mathrm{~g} / \mathrm{L}\end{array}$ \\
\hline Styrene & $\begin{array}{l}\mathrm{IC}_{50}-\mathrm{M} \text { is } 0.211 \mathrm{~g} / \mathrm{L} \text { and } \mathrm{IC}_{50}-\mathrm{S} \text { is } 0.136 \mathrm{~g} / \mathrm{L} \text {. Threshold IC is } 14.94-34.52 \mathrm{mg} / \mathrm{L} \text {, above which } \\
\text { styrene inhibits sludge activity }\end{array}$ \\
\hline 2,4-dichlorophenol & $\begin{array}{l}\text { slightly inhibited sOUR uptake at } 1-20 \mathrm{mg} / \mathrm{L} \text {, almost no effect on COD removal efficiency at } 1 \text { - } \\
10 \mathrm{mg} / \mathrm{L} \text { and slightly decreased at more than } 10 \mathrm{mg} / \mathrm{L} \text {. }\end{array}$ \\
\hline 2,4-dinitrophenol & COD removal decreased btw 5-20 mg/L, sOUR uptake increased at 5-20mg/L \\
\hline 2,6-dichlorophenol & 20mg/L reduced nitrification significantly \\
\hline 3,5-dichlorophenol & $6-30 \mathrm{mg} / \mathrm{L}$ inhibited up to $80 \%$ of intact cells and $25-49 \%$ of active cells in a batch reactor \\
\hline Naphtenic acids & up to $50 \%$ inhibition at $0-10 \mathrm{mg} / \mathrm{L}$ \\
\hline p-cresol & above 100 mg/L severely inhibited nitrification \\
\hline
\end{tabular}

the presence of toxicants. Thus, the oxygen uptake decrease is observed as a direct indication of toxicity (Tzoris and Hall, 2006). Based on the OUR measurements of the activated sludge, the standardized respirometric tests have been established (Cokgor et al., 2007). The degradation extent in an aerobic reactor is highly dependent on dissolved oxygen (Wilén and Balmér, 1999), temperature (Vogelaar et al., 2002), organic matter, nutrients and micronutrients (Pamukoglu and Kargi, 2007). These parameters are also important for consideration of reasonable operation of wastewater treatment plants.

The purpose of this paper is to present and analyse experimental results on the inhibitory effects of several organic compounds on municipal activated sludge activity by use of OUR kinetics. From literature review, it can be concluded that most organic compounds causing severe biomass inhibition are polar, that is they large dipole moments. Moreover, compounds with aromatic ring appear to be hardly biodegradable to microbial community. Other properties that could govern an impact of organic substance on biomass are solubility and volatility of compounds. The current study investigates the influence of these parameters on activated sludge systems by analyzing the correlation between physico-chemical properties or structure of organic substance and its toxicity. The compounds used are: phenol, nitrophenol, resorcinol, dioxane, acetonitrile, benzotriazole, toluene, styrene, cyclohexane, paraxylene, benzene, hexane, tetrachloromethane and napthalene.

\section{MATERIALS AND METHODS}

\section{Source of waste activated sludge and operation}

The waste activated sludge used in this research was sampled from sedimentation tank of Astana municipal wastewater treatment plant. The main objective of the experiment was to determine the rate of oxygen consumption of biomass which is attributed to the biodegradation of organic carbon by heterotrophic bacteria (biomass). $1 \mathrm{~L}$ of activated sludge is placed under aeration overnight 
(DO $>4 \mathrm{mg} \mathrm{L}-1$ ) to reach endogenous conditions. Then, $500 \mathrm{~mL}$ of activated sludge is placed at a 1 L Erlenmeyer flask under continuous aeration and agitation so that the DO level remains high. DO of the liquid solution was measured using dissolved oxygen meter. The aeration was achieved by using blowers to provide air at a rate of $20 \mathrm{~L} / \mathrm{min}$ each. Agitation was provided through use of magnetic stirrer. The temperature of activated sludge solution was maintained at $20 \pm 2^{\circ} \mathrm{C}$ and $\mathrm{pH}$ at 7.5 \pm 0.4 . The temperature was measured using thermometer designed to measure temperature in liquids (range $0-40^{\circ} \mathrm{C}$ ). The $\mathrm{pH}$ of solution was measured using $\mathrm{pH}$ meter. Phosphate buffer solution was used to calibrate $\mathrm{pH}$ meter. If necessary, $\mathrm{NaHCO}_{3}$ was added to adjust $\mathrm{pH}$. Oxygen consumption only due to COD removal and not nitrification was studied in this research. For this, allylthiourea was added to waste activated sludge solution in order to inhibit nitrification process. Acetic acid or sodium acetate was used as a carbon source for biomass. The TSS (total suspended solids) of activated sludge was determined through manual filtration of $10 \mathrm{ml}$ sample activated sludge on GF/C filters Whatman and further drying in furnace at $105^{\circ} \mathrm{C}$.

In the proposed investigation in inhibitory effects of 13 organic compounds on municipal activated sludge activity by use of OUR kinetics were presented and analysed. The polar compounds are phenol, nitrophenol, resorcinol, dioxane, acetonitrile and benzotriazole. Nonpolar tested compounds include toluene, styrene, cyclohexane, paraxylene, benzene, and hexane, tetrachloromethane. The properties of the compounds used in this research are summarized in Table 2.

Table 2. Organic compounds properties.

\begin{tabular}{llllll}
\hline & $\begin{array}{l}\text { Dipole } \\
\text { (debye) }\end{array}$ & $\begin{array}{l}\text { moment } \\
\text { Solubility in water } \\
(\mathrm{mg} / \mathrm{L}) @ 25^{\circ} \mathrm{C}\end{array}$ & $\begin{array}{l}\text { Vapor } @ 25^{\circ} \mathrm{C}(\mathrm{mmHg}) \\
\text { Form }\end{array}$ & $\begin{array}{l}\text { Density } \\
\text { (g/ml) }\end{array}$ \\
\hline Phenol & 1.24 & 82800 & 0.35 & Solid & - \\
4-nitrophenol & 5.43 & 11600 & 0.0005 & Solid & - \\
Toluene & 0.31 & 535 & 24.8 & Liquid & 0.87 \\
Styrene & 0.13 & 300 & 6.4 & Liquid & 0.91 \\
Cyclohexane & 0 & 55 & 96.9 & Liquid & 0.78 \\
$\begin{array}{l}\text { P-xylene } \\
\text { 1-3 Dixydroxylbenzene }\end{array}$ & 0.07 & 162 & 8.84 & Liquid & 0.86 \\
(resorcinol) & 2.09 & 717000 & 0.000489 & Solid & - \\
Benzene & 0 & 1790 & 94.8 & Liquid & 0.88 \\
Hexane & 0.08 & 9.5 & 153 & Liquid & 0.66 \\
1,4 Dioxane & 0.45 & 100000 & 38.1 & Liquid & 1.03 \\
Acetonitrile & 3.44 & 800000 & 88.8 & Liquid & 0.71 \\
Benzotriazole & 1.46 & 19800 & 0.04 & Solid & - \\
CCl4 & 0 & 1160 & 115 & Liquid & 1.59 \\
\hline
\end{tabular}

\section{Analysis}

The biomass is placed in a BOD flask under very mild agitation (magnetic stirrer) but without any aeration and DO is recorded with oxygen meter for 5-10 minutes. This activity corresponds to the endogenous respiration $\left(\mathrm{OUR}_{\text {endogenous }} \mathrm{mgO}_{2} / \mathrm{L} \mathrm{h}\right.$ ). After that $250 \mathrm{mg} \mathrm{COD} / \mathrm{L}$ of acetic acid (or sodium acetate) is added to the biomass and measurements are repeated after 30 and 60 minutes. The decrease of DO with time will be very fast owing to the presence of readily biodegradable organic matter. By plotting DO versus time and calculating the slope, the OUR $\mathrm{max}_{\text {can }}$ be calculated for each experiment. By subtracting the OUR endogenous from the $\mathrm{OUR}_{\max }$ the activity related solely to 
the oxidation of acetic acid is obtained (units $\mathrm{mgO}_{2}$ /gTSS h). The simplified bioreaction, which takes place by heterotrophic bacteria is the following:

$$
\text { Organic carbon }+\mathrm{O}_{2}+\text { nutrients } \rightarrow \mathrm{CO}_{2}+\mathrm{H}_{2} \mathrm{O}+\text { new biomass }
$$

The results need to be normalized to the amount of bacteria present in the sludge. Bacteria are quantified by determining the total suspended solids (TSS) of the activated sludge. The filters used to quantify total suspended solids and volatile suspended solids are the GF/C. When the OUR is normalized to the TSS it is referred to as the specific oxygen uptake rate (sOUR $\mathrm{mgO}_{2} / \mathrm{gTSS} h$ ). The results also is corrected for temperature. The sOUR results are reported to the reference temperature of $20^{\circ} \mathrm{C}$ using the following temperature correction equation (de Fabio et al., 2013):

$$
\mathrm{sOUR}_{20}=\mathrm{sOUR}_{\mathrm{T}} / 1.09^{(\mathrm{T}-20)}
$$

\section{RESULTS AND DISCUSSION}

The results are shown in Figures 1-13. In order to better show the inhibition and to eliminate the experimental errors the inhibition greater than $20 \%$ was chosen as a reference point (inhibition limit). Furthermore, the limit of $1000 \mathrm{mg} / \mathrm{L}$ (concentration limit) was considered to be more appropriate in terms of comparison and making it more realistic. Furthermore, the solubility limit is included in the graph, which is useful for the discussion of the results. Solubility limit is shown in cases where it is within the initial concentration range.

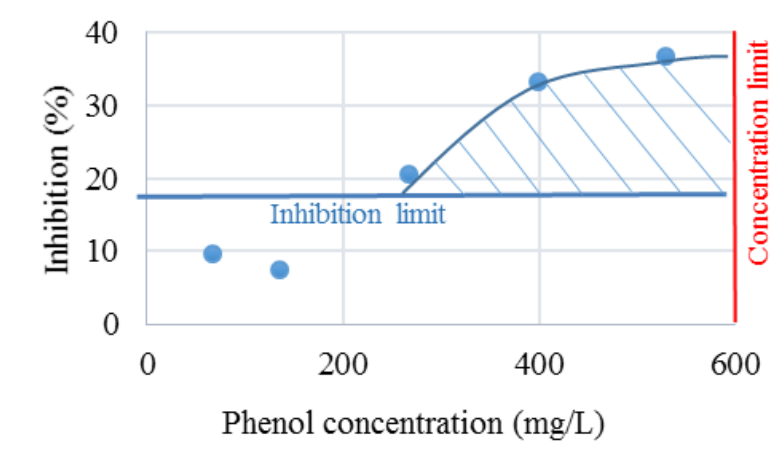

Figure 1. Inhibition percent versus phenol concentration (mg/L).

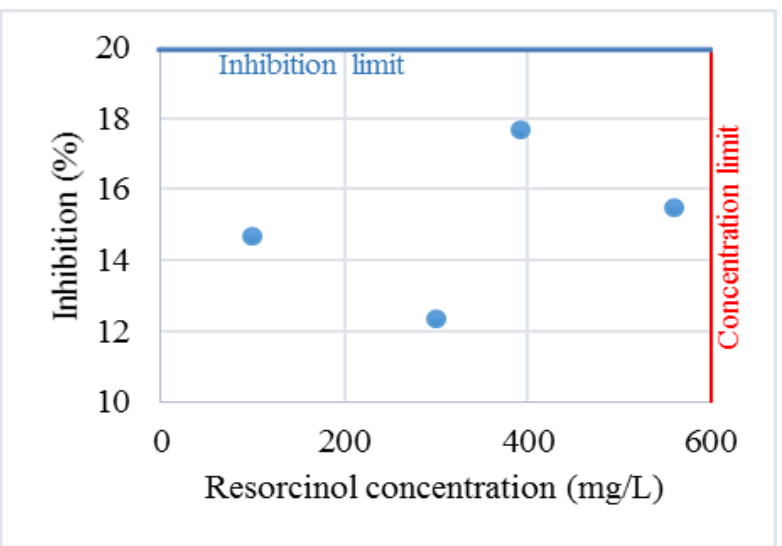

Figure 3. Inhibition percent versus resorcinol concentration (mg/L).

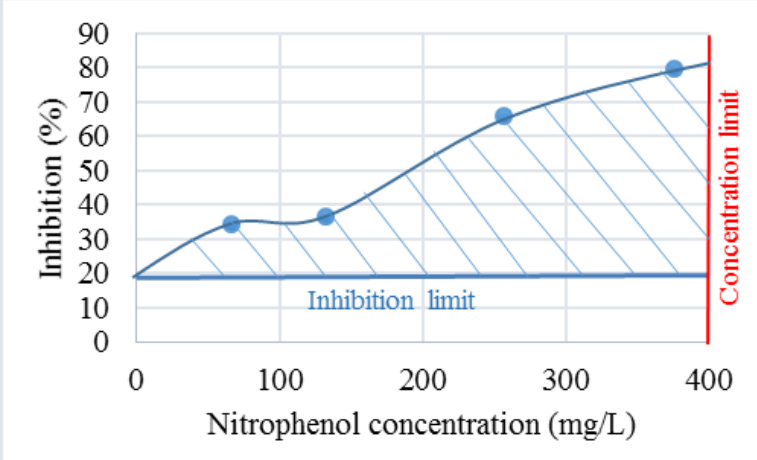

Figure 2. Inhibition percent versus nitrophenol concentration (mg/L).

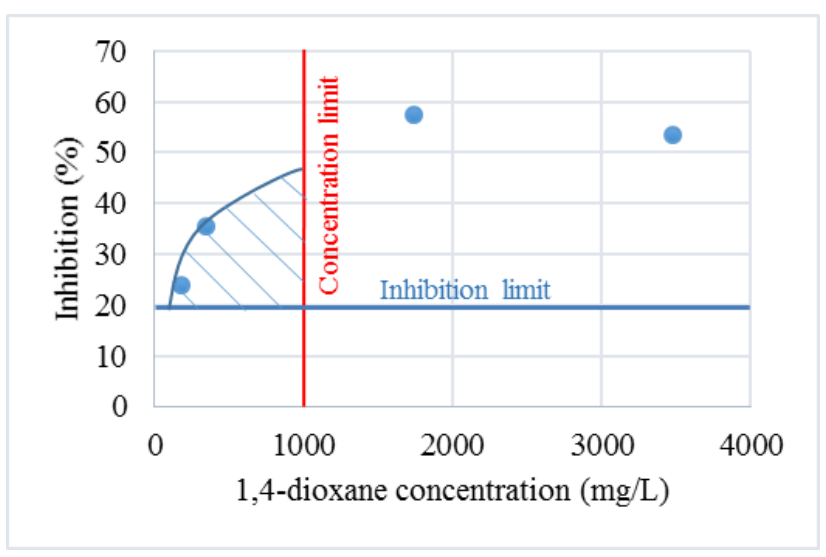

Figure 4. Inhibition percent versus 1,4dioxane concentration (mg/L). 


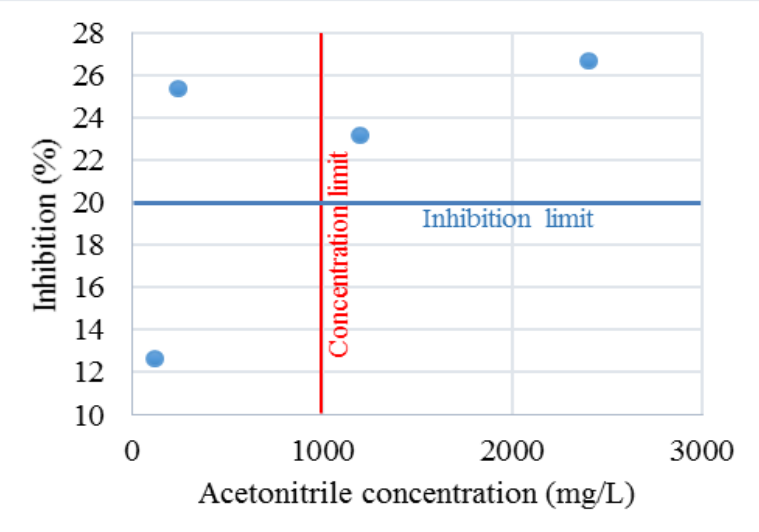

Figure 5. Inhibition percent versus acetonitrile concentration (mg/L).

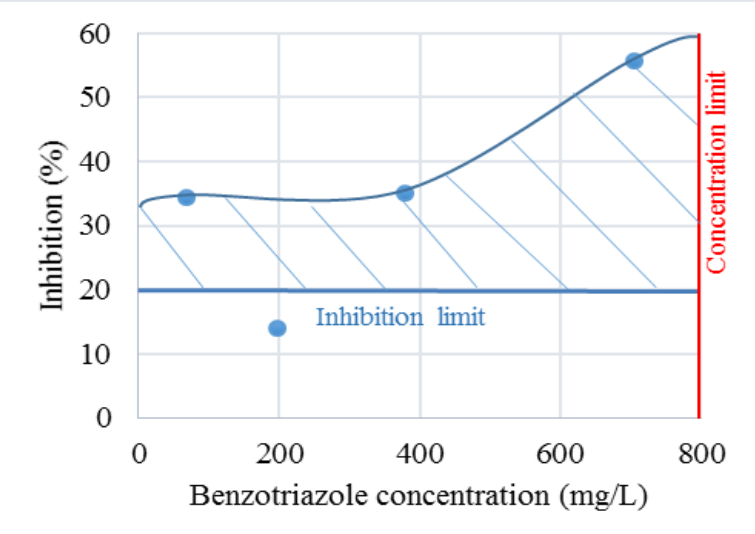

Figure 7. Inhibition percent versus benzotriazole concentration (mg/L).

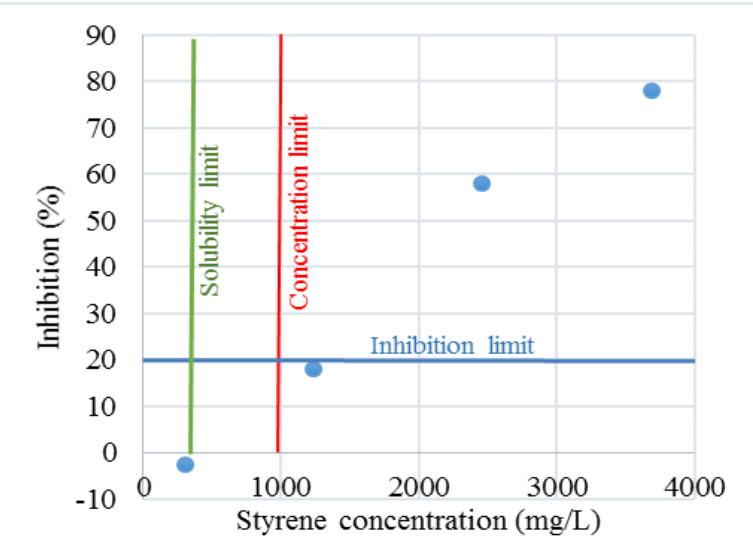

Figure 9. Inhibition percent versus styrene concentration (mg/L).

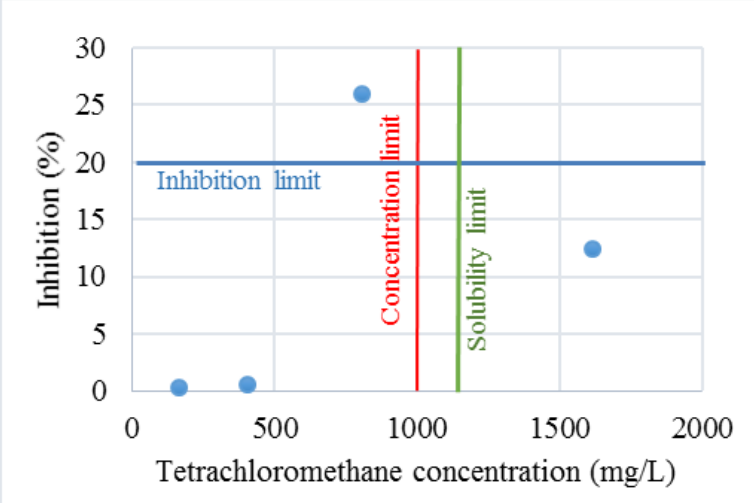

Figure 6. Inhibition percent versus tetrachloromethane concentration (mg/L).

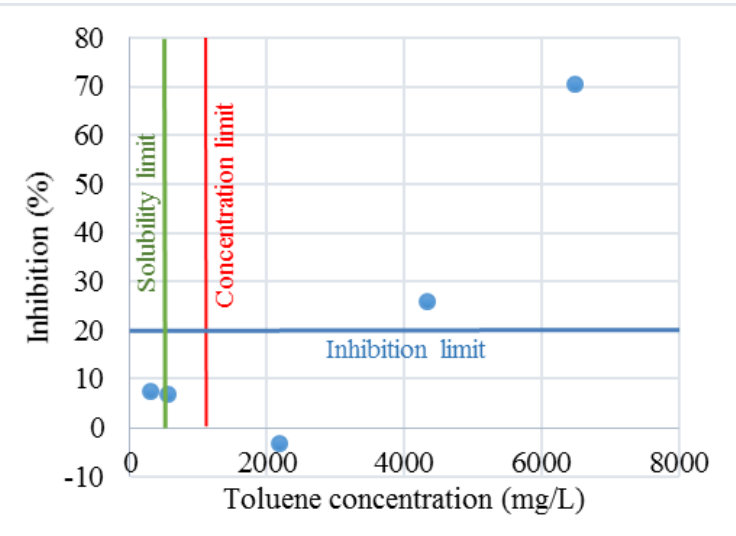

Figure 8. Inhibition percent versus toluene concentration (mg/L).

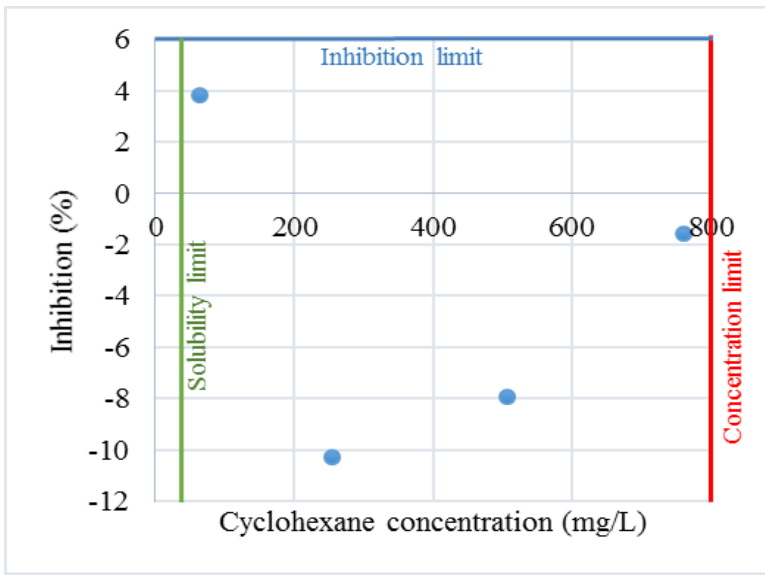

Figure 10. Inhibition percent versus cyclohexane concentration (mg/L). 


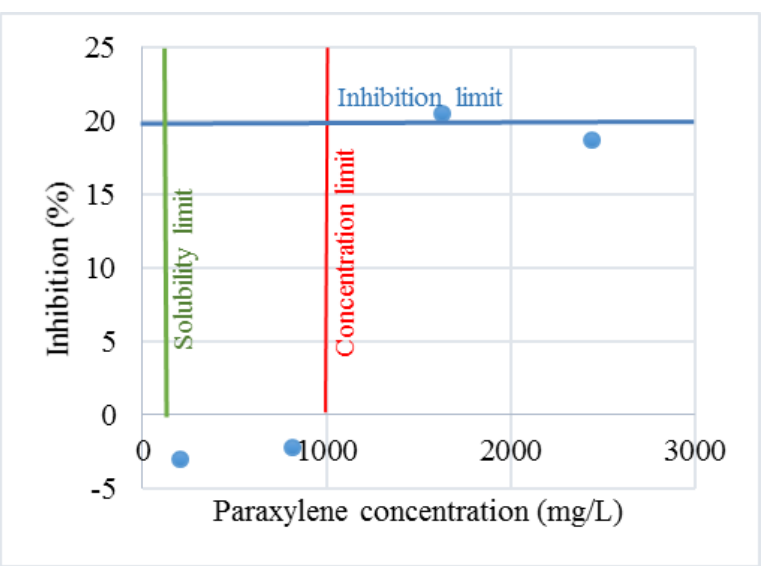

Figure 11. Inhibition percent versus paraxylene concentration (mg/L).

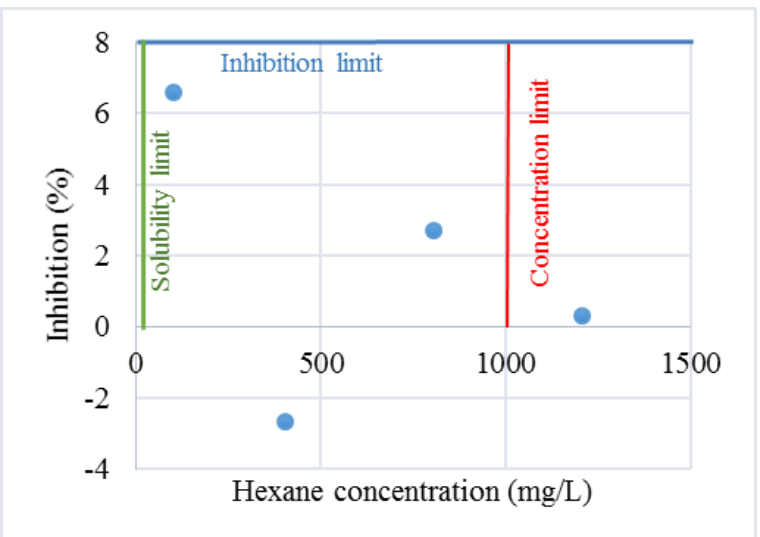

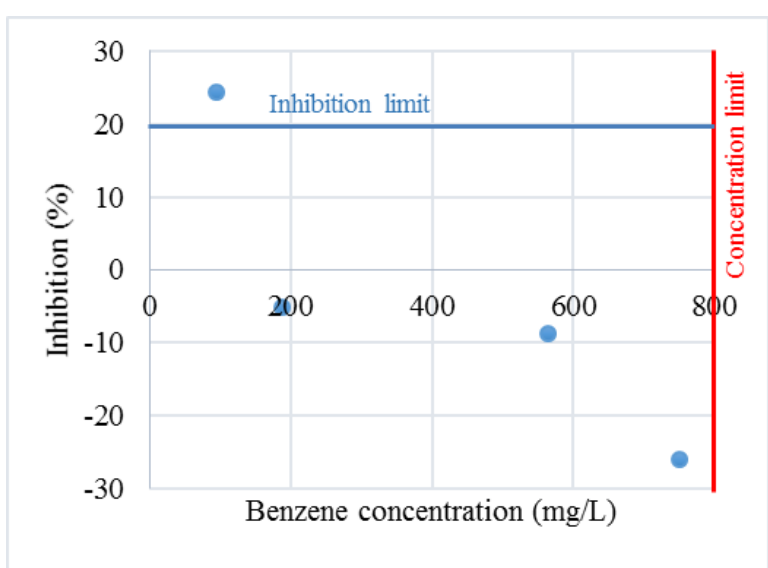

Figure 12. Inhibition percent versus benzene concentration $(\mathrm{mg} / \mathrm{L})$.

Figure 13. Inhibition percent versus hexane concentration (mg/L).

In overall, 11 compounds out of 13 has shown inhibition of biomass activity. In particular, there is a clear indication of inhibition in cases of phenol, nitrophenol, benzotriazole and 1,4-dioxane with $40 \%, 80 \%, 60 \%$ and $50 \%$ inhibitions respectively. From the dipole moments of compounds in Table 2, it is clear that these chemicals are indeed polar and have the ring in their molecular structure. The polarity of 1,4-dioxane can be questioned. Although overall dipole moment of 1,4dioxane (0.45Debye), there is a double bond between oxygen and carbon $(\mathrm{C}=\mathrm{O})$ in the molecule which is indeed polar. This means that molecules of 1,4-dioxane are locally polarized. This also can be seen from the solubility of 1,4-dioxane $(100 \mathrm{~g} / \mathrm{L})$, it is considerably higher than the solubility of other compounds. Taking those compounds with inhibition and overall high polarity and excluding the locally polarized 1,4-dioxane with uncertain polarization effect, the following dependency of inhibition on dipole moment is observed on Figure 14. It is clearly seen that the higher polarity causes the more extent inhibition. 


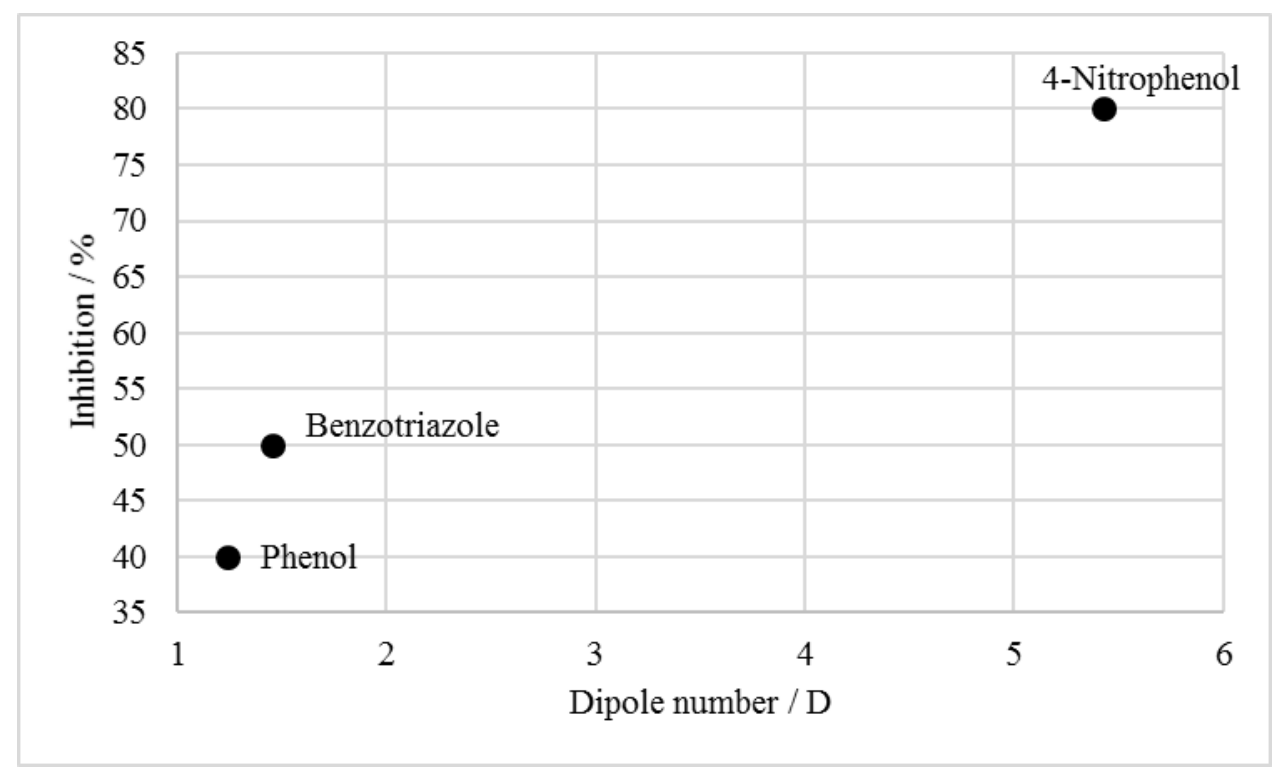

Figure 14. Dependency of inhibition on dipole moment.

Acetonitrile has the presence of inhibition but it is decent only beyond the $1000 \mathrm{mg} / \mathrm{L}$ concentration and the molecule does not contain the ring structure. Majority of polar compounds except resorcinol show significant inhibition of activated sludge. It could be assumed that the experimental error occurred during the measurements with the use of this compound. So, it is suggested to investigate the effect of resorcinol inhibition further. Among the non-polar compound there are the inhibitions in cases of toluene and styrene up to $70 \%$ and $79 \%$. However, these inhibitions can be achieved by increasing the concentrations to $6000 \mathrm{mg} / \mathrm{L}$ and $3700 \mathrm{~g} / \mathrm{L}$, which is above their solubility limit 535 and $300 \mathrm{mg} / \mathrm{L}$ (Table 2). In general in low concentrations majority of compounds with high dipole moments exhibit clear inhibition, while all non-polar compounds do not show any appearance of inhibition. It can be stated that majority of polar compounds influence negatively to the activity of biomass. This tendency increases as the dipole moment of the molecule increases. In terms of solubility the compounds that have an inhibitory effect have very high solubility in water. Mainly, if the solubility limit was reached there is no inhibition, on the other hand the styrene and toluene are a clear examples of reverse process. This phenomenon requires more detailed investigation. The volatility of the compounds do not play significant role since the duration of experiments was insufficient to see its effect. In order to examine the impact of volatility more retention time should be taken into account.

\section{CONCLUSION}

To sum up, 11 compounds out of 13 has shown inhibition of biomass activity. The hypothesis is that polarity, solubility and in lesser extend volatility should dictate the intensity of inhibition. Indeed, the results clearly demonstrated that polar compounds heavily inhibit biomass activity, ranging up to $80 \%$ inhibition in the case of p-nitrophenol at $400 \mathrm{ppm}$. Out of the nonpolar compounds that have been tested toluene and styrene showed positive inhibition up to $80 \%$ but in very high concentrations and above their solubility limit. On the contrary, cyclohexane and hexane do not show any significant inhibition. The results are less clear in the cases of naphthalene, tetrachloromethane and paraxylene benzene. In general, the results show that compounds with higher dipole moment and solubility exhibit higher inhibition in comparison to the rest of compounds. Furthermore, some of the less volatile compounds have displayed higher inhibition but the effect of volatility cannot be clearly established in these experiments since low residence time 
systems were run. Volatility could be an important factor contributing to biomass inhibition in high residence time systems. Finally, the results showed that inhibition can occur even or only if the solubility limits are exceeded, a phenomenon that deserves further investigation.

\section{REFERENCES}

Babaee, R., Bonakdarpour, B., Nasernejad, B. and Fallah, N. 2010. Kinetics of styrene biodegradation in synthetic wastewaters using an industrial activated sludge. Journal of hazardous materials, 184(1), 111-117.

Cai, B., Xie, L., Yang, D. and Arcangeli, J.P. 2010. Toxicity evaluation and prediction of toxic chemicals on activated sludge system. Journal of hazardous materials, 177(1), 414-419.

Cokgor, E.U., Ozdemir, S., Karahan, O., Insel, G. and Orhon, D. 2007. Critical appraisal of respirometric methods for metal inhibition on activated sludge. Journal of hazardous materials, 139(2), 332-339.

Kraigher, B., Kosjek, T., Heath, E., Kompare, B. and Mandic-Mulec, I. 2008. Influence of pharmaceutical residues on the structure of activated sludge bacterial communities in wastewater treatment bioreactors. Water Research, 42(17), 4578-4588.

Ramteke, L.P. and Gogate, P.R. 2015. Synthesis and characterization of modified activated sludge for biological oxidation with isolation studies and performance evaluation. Separation and Purification Technology, 141, 179-187.

Pamukoglu, M.Y. and Kargi, F. 2007. Copper (II) ion toxicity in activated sludge processes as function of operating parameters. Enzyme and Microbial Technology, 40(5), 1228-1233.

Surerus, V., Giordano, G. and Teixeira, L.A.C. 2014. Activated sludge inhibition capacity index. Brazilian Journal of Chemical Engineering, 31(2), 385-392.

Tzoris, A. and Hall, E.A.H. 2006. Rapid detection of toxicity in wastewater: Recent developments with manometric respirometry. Analytica chimica acta, 573, 147-157.

Vogelaar, J.C.T., Bouwhuis, E., Klapwijk, A., Spanjers, H. and Van Lier, J.B. 2002. Mesophilic and thermophilic activated sludge post-treatment of paper mill process water. Water Research, 36(7), 1869-1879.

Wilén, B.M. and Balmér, P. 1999. The effect of dissolved oxygen concentration on the structure, size and size distribution of activated sludge flocs. Water Research, 33(2), 391-400.

Yao, Y., Guan, J., Tang, P., Jiao, H., Lin, C., Wang, J., Lu, Z., Min, H. and Gao, H. 2010. Assessment of toxicity of tetrahydrofuran on the microbial community in activated sludge. Bioresource technology, 101(14), 5213-5221. 